\title{
Study on the Untapped Potential of Rural Women
}

\author{
Megha S Shetty \\ (Industrial and Production/KLE Technological University, India)
}

\begin{abstract}
For years now, women have been transforming society through their growing contribution to the world economy. Their participation rate in the labor force today nearly equals men. Globally, women are earning higher credentials, yet in spite of these achievements, there is a persistent lack of rural women participation in top leadership roles, indicative of work still needed to address the barriers and obstacles that make it harder for rural women to study further, take up jobs and take up challenging roles in a company. Rural women face unique challenges and limitations. They have, on average, lower levels of literacy and education than men, and generally have less freedom within households and communities. At the same time, women are responsible for managing the household, raising the children, contributing to some part of the family business as well as engaging in community activities more than men The potential of these women isn't being utilized as they don't get the same exposure as urban women nor do they receive the same level of education.
\end{abstract}

Keywords - Aptitude, Skill, Talent, Potential of women, Rural women.

\section{INTRODUCTION}

Rural women constitute one-fourth of the world's population. They are leaders, producers, entrepreneurs and service providers, and their contributions are vital to the well-being of families, communities and economies, and the achievement of the Millennium Development Goals. Rural women account for a great proportion of the agricultural labour force, produce the majority of food grown, especially in subsistence farming, and perform most of the unpaid care work in rural areas. Agriculture provides a livelihood for 86 percent of rural women and men and employment for about 1.3 billion smallholder farmers and landless workers; 43 percent are women ${ }^{[1]}$. Yet, their rights and contributions have been largely overlooked. Potential generally refers to a currently unrealized ability. It can also mean abilities that may be developed and lead to future success or usefulness. Human potential can be measured by determining the aptitude, skill and talent of the person. A skill is the ability to carry out a task with pre-determined results often within a given amount of time, energy, or both. An aptitude is a component of a competence to do a certain kind of work at a certain level. Outstanding aptitude can be considered "talent".

\section{PROBLEM DEFINITION AND OBJECTIVES OF THE STUDY}

- To understand and realize the skill and aptitude that the rural women possess and determine how they can contribute to the rural development

- To identify the potential (aptitude and skill) of rural women and study the predominantly prevailing skills that contribute to rural development

- To identify the challenges associated with utilizing the untapped potential of women for rural development.

\section{METHODOLOGY}

For this research project, comparative study has been followed. It is a research methodology in the social sciences that aims to make comparisons across different cultures or people. Comparative research, simply put, is the act of comparing two or more things with a view to discovering something about one or all of the things being compared. This technique often utilizes multiple disciplines in one study. When it comes to method, the majority agreement is that there is no methodology peculiar to comparative researchThe primary research was done by conducting a survey with a questionnaire of 25 questions. The survey was conducted for 120 women out of 60 were rural women and the remaining 60 were urban women. This questionnaire consisted of skill and aptitude questions. 


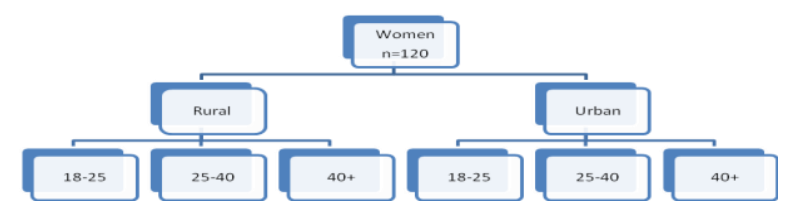

Fig1. Categorization of women for the survey.

IV. QUESTIONNAIRE

The survey was conducted in Hubli-Dharwad District of Karnataka State. The questionnaire consisted of questions to check on aptitude and skills like leadership, social, communication, adaptability, cooperation, dependability etc.

V. DATA ANALYSIS AND INTERPRETATION

5.1. Comparative charts between rural and urban women

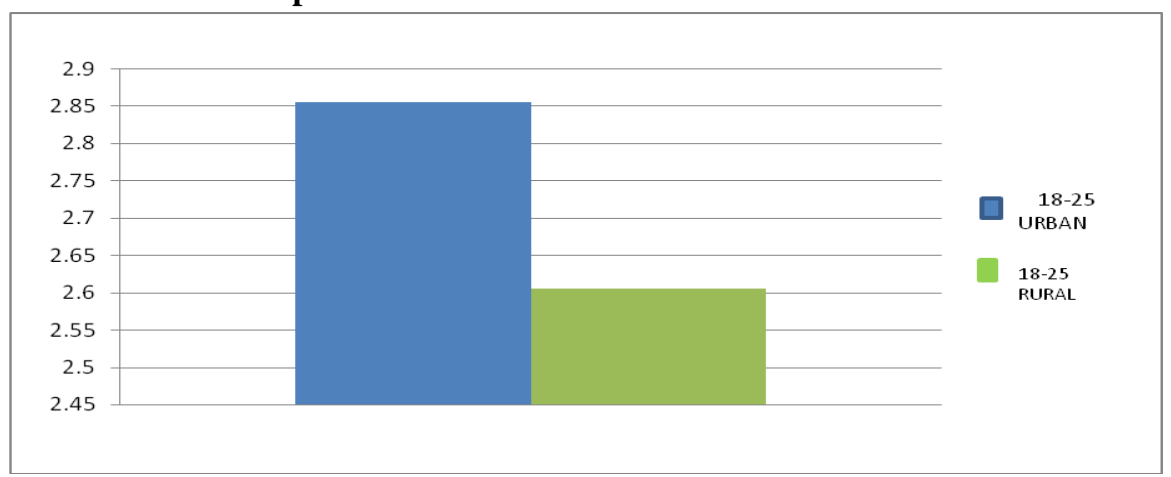

Fig.2 Skill \& aptitude for 18-25 year old women

Interpretation: From the above chart it is can be observed that the skill and aptitude is much higher for urban women of 18-25 year old than rural women of the same age. Urban women of this age want to receive more education and are willing to take risks when it comes to their careers.

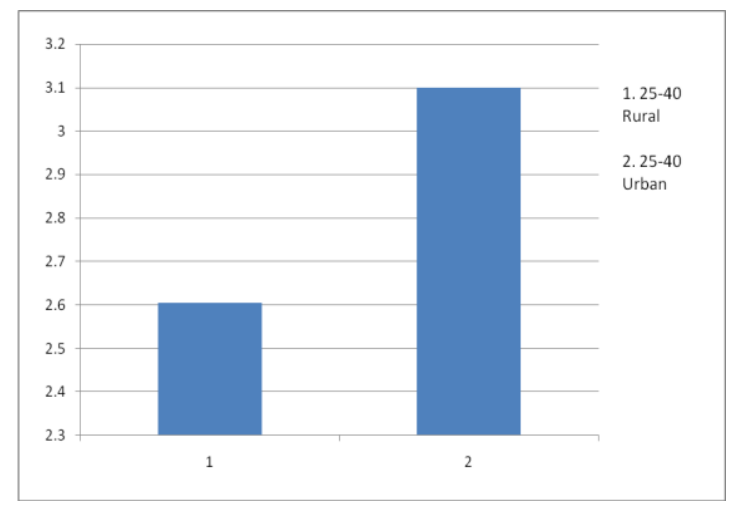

Fig 3. Skill and aptitude for 25-40 year old women

Interpretation: The rural women in this category were not sure about their abilities. They were interested in their marriage than being independent and earning their own livelihood. Whereas the urban women were clearly career oriented, independent, had great communication skills and also gave their career/education more importance. 


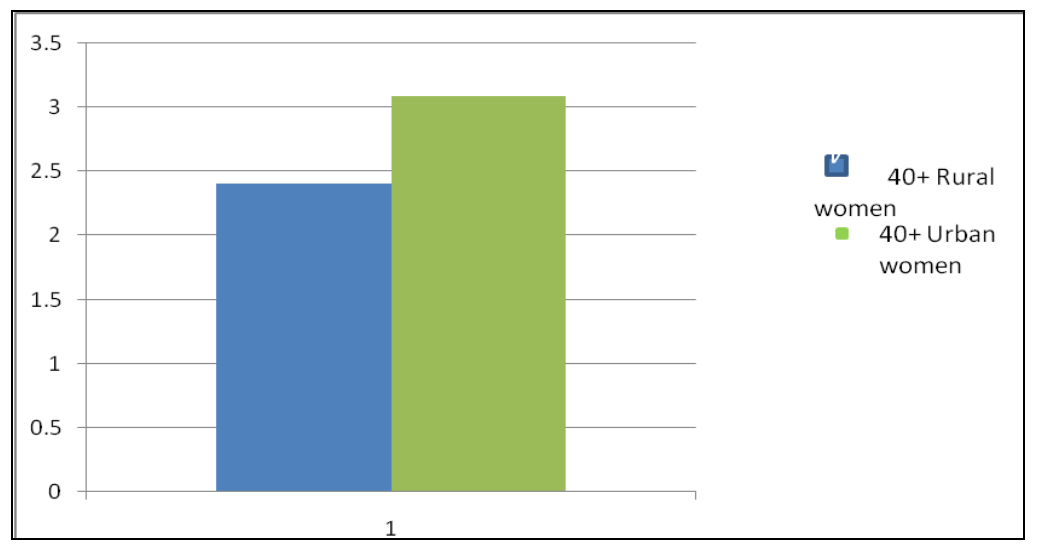

Fig 4. Skill and aptitude for $40+$ year old women

Interpretation: In the last of category of 40+ year old women, the urban women wanted to work on their jobs more than the rural women. Both women wanted to give more importance to their families than work. They didn't want to take risks when it came to their work.

\subsection{Comparative charts of rural women of different categories}

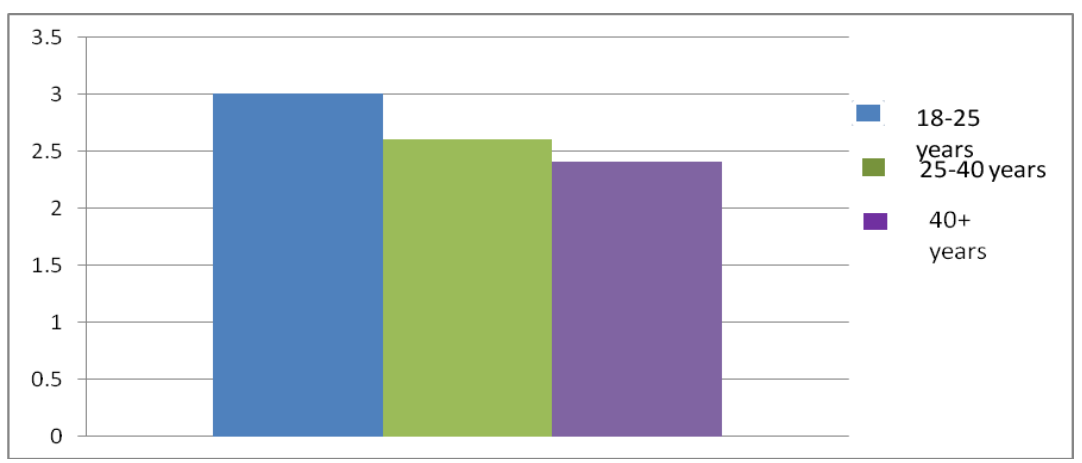

Fig 4: Skill and aptitude comparison between the rural women

Interpretation: From the given comparative chart it can be observed that the 18-25 year old women have the highest aptitude and skill and therefore they will have the highest potential. These are the women who are interested in higher education and becoming independent in life. They want to overcome any hurdles that come in their way and want to compete with the urban women. They also want to provide for their families. These women have the potential in them to survive in this competitive world. The other category women are already married and well settled in their lives therefore they don't want to take any risks in their lives. Although they do earn a livelihood through agriculture they are not utilizing their entire potential.

\section{CONCLUSION}

We should creating conditions to unlock the full potential of rural women. Presently, there is significant potential to raise the labor participation rates of women across the country. The reasons why rural women choose to remain at their current level despite their skills and aptitude is due lack of role models, exclusion from the informal networks, not having enough opportunities. Of all the forces that hold rural women back, however, none of them are as powerful as beliefs. While social activists have worked hard to eliminate the gender discrimination, women still face the destructive force of mindsets that limit opportunity for these rural women. Women also face lifestyle issues where they have to choose between family and work. They sometimes don't utilize the opportunities given to them. They should be made aware of all the government schemes available especially for them. The biggest barrier for rural women is their own mindset that halts their progress. The mindset that they can't do a particular job is what is holding them back. While urban women remain highly confident of their qualifications throughout their careers, rural women are on average less satisfied than urban women with their chosen professions and jobs. As rural women get older, their desire to move to the next level dissipates faster than urban women. At all ages, urban women want to take on more responsibility in their 
profession and have greater control over their life. They must get the confidence and grit to move on to the next level just like the urban women. Urban also know how to manage both work and marriage whereas rural women think its one or the other. Eradication of these thoughts will lead to utilization of the untapped potential of rural women.

\section{ACKNOWLEDGEMENTS}

I would like to thank Dr. Sanjay V Kotabagi for giving me this opportunity to work in the Social science space. I would like to extend my gratitude Mrs. Uma for guiding me throughout this research. Special Thanks Ar. Shamika Shetty for helping me with the questionnaire and survey.

[1] Unlocking the full potential of women at work by Joanna Barsh and Lareina Yee

[2] www.hr-survey.com

[3] http://www.occupationsguide.cz 